\title{
Article \\ The Role of Predictive Models in the Assessment of the Poor Outcomes in Pediatric Acute Liver Failure
}

\author{
Tudor Lucian Pop ${ }^{1,2, *}$, , Cornel Olimpiu Aldea ${ }^{3}$, Dan Delean ${ }^{3}$, Bogdan Bulata ${ }^{3}{ }^{-D}$, Dora Boghiţoiu ${ }^{4,5}$, \\ Daniela Păcurar ${ }^{4,5}$, Coriolan Emil Ulmeanu ${ }^{4,5}$ and Alina Grama ${ }^{1,2}$
}

Citation: Pop, T.L.; Aldea, C.O.; Delean, D.; Bulata, B.; Boghiţoiu, D.; Păcurar, D.; Ulmeanu, C.E.; Grama, A. The Role of Predictive Models in the Assessment of the Poor Outcomes in Pediatric Acute Liver Failure. J. Clin. Med. 2022, 11, 432. https:// doi.org/10.3390/jcm11020432

Academic Editor: Paolo Aseni

Received: 14 December 2021

Accepted: 13 January 2022

Published: 15 January 2022

Publisher's Note: MDPI stays neutral with regard to jurisdictional claims in published maps and institutional affiliations.

Copyright: (c) 2022 by the authors. Licensee MDPI, Basel, Switzerland. This article is an open access article distributed under the terms and conditions of the Creative Commons Attribution (CC BY) license (https:// creativecommons.org/licenses/by/ $4.0 /)$.
1 2nd Pediatric Discipline, Department of Mother and Child, Iuliu Hatieganu University of Medicine and Pharmacy, 400012 Cluj-Napoca, Romania; gramaalina16@yahoo.com

2 Center of Expertise in Pediatric Liver Rare Disorders, 2nd Pediatric Clinic, Emergency Clinical Hospital for Children, 400177 Cluj-Napoca, Romania

3 Pediatric Nephrology, Dialysis and Toxicology Clinic, Emergency Clinical Hospital for Children, 400177 Cluj-Napoca, Romania; cornelaldea65@yahoo.com (C.O.A.); ddelean2003@yahoo.com (D.D.); iggbie@gmail.com (B.B.)

4 Department of Pediatrics, Carol Davila University of Medicine and Pharmacy, 020021 Bucharest, Romania; dora.boghitoiu@umfcd.ro (D.B.); daniela.pacurar@umfcd.ro (D.P.); coriolanulmeanu@yahoo.com (C.E.U.)

5 Department of Pediatrics, Grigore Alexandrescu Emergency Clinical Hospital for Children, 011743 Bucharest, Romania

* Correspondence: tudor.pop@umfcluj.ro

\begin{abstract}
Objectives: In children, acute liver failure (ALF) is a severe condition with high mortality. As some patients need liver transplantation (LT), it is essential to predict the fatal evolution and to refer them early for LT if needed. Our study aimed to evaluate the prognostic criteria and scores for assessing the outcome in children with ALF. Methods: Data of 161 children with ALF $(54.66 \%$ female, mean age $7.66 \pm 6.18$ years) were analyzed based on final evolution (32.91\% with fatal evolution or LT) and etiology. We calculated on the first day of hospitalization the PELD score (109 children), MELD, and MELD-Na score (52 children), and King's College Criteria (KCC) for all patients. The Nazer prognostic index and Wilson index for predicting mortality were calculated for nine patients with ALF in Wilson's disease (WD). Results: PELD, MELD, and MELD-Na scores were significantly higher in patients with fatal evolution $(21.04 \pm 13.28$ vs. $13.99 \pm 10.07, p=0.0023 ; 36.20 \pm 19.51$ vs. $20.08 \pm 8.57, p<0.0001$; and $33.07 \pm 8.29$ vs. $20.08 \pm 8.47, p<0.0001$, respectively). Moreover, age, bilirubin, albumin, INR, and hemoglobin significantly differed in children with fatal evolution. Function to etiology, PELD, MELD, MELD-Na, and KCC accurately predicted fatal evolution in toxic $\operatorname{ALF}(25.33$ vs. $9.90, p=0.0032 ; 37.29$ vs. $18.79, p<0.0001 ; 34.29$ vs. $19.24, p=0.0002$, respectively; with positive predicting value $100 \%$, negative predicting value $88.52 \%$, and accuracy $89.23 \%$ for King's College criteria). The Wilson index for predicting mortality had an excellent predictive strength $(100 \%$ sensibility and specificity), better than the Nazer prognostic index. Conclusions: Prognostic scores may be used to predict the fatal evolution of ALF in children in correlation with other parameters or criteria. Early estimation of the outcome of ALF is essential, mainly in countries where emergency LT is problematic, as the transfer to a specialized center could be delayed, affecting survival chances.
\end{abstract}

Keywords: acute liver failure; children; prognosis; pediatric end-stage liver model; model for endstage liver disorder; King's College Hospital criteria

\section{Introduction}

In children, acute liver failure (ALF) is a rare but severe disorder associated with high mortality [1,2]. Pediatric ALF (PALF) differs from adults due to the type and diversity of causes and late appearance of hepatic encephalopathy (HE) [1]. The etiology of ALF in children varies according to age and worldwide location [3-7]. Children with autoimmune hepatitis (AIH), hepatitis A virus (HAV) infection, and acetaminophen overdose are more 
likely to survive without liver transplantation (LT). On the contrary, neonates with Herpes simplex virus (HSV) infection and ALF have 10\% recovery chances only with antiviral treatment [8,9]. In PALF, $20 \%$ of those who never developed HE died or underwent LT, and those with grade IV HE had a better outcome than those who progressed to grade IV [10]. During the last decades, spontaneous survival in patients with ALF increased from 17 to $48 \%$ [11]. Moreover, survival after LT increased from 10-56 to 60-86\% [11-14].

Nowadays, $10-15 \%$ of LT indications in children are in ALF patients [3,15]. It is difficult to decide to transplant a child with ALF as it is impossible to know if the patient may survive without LT [16]. LT would offer a chance of survival to the high-risk ALF patients, but some patients would be at risk of unnecessary surgery and lifelong immunosuppression. Successful conservative management would save low-risk ALF patients from unnecessary surgery $[11,12,17]$.

Accurate prognostic scores are needed to discriminate patients with poor outcomes from those who will recover spontaneously or with a specific treatment $[3,12,18,19]$. More and more, there is a need to optimize the available organs and resources [3]. The moment of the listing is critical for the success of LT in patients with ALF [12]. The availability of organs or living donors dictates when a patient with pediatric ALF is transplanted once the patient is listed, and varies based on a center experience with different LT types. Moreover, some patients with LT would survive without it [20].

Researchers developed, evaluated, and revised scoring systems to aid the prediction of the ALF outcome. An accurate model would require a large cohort and a multicenter approach [16]. The predictive models are based on features derived from analysis of ALF cohorts, treated conservatively, without LT [21]. Until now, many factors proved to be possible prognostic markers for an unfavorable outcome in pediatric ALF: age under ten years, etiology (viral infections, Wilson's disease-WD), the presence of grade III/IV $\mathrm{HE}$, a quick decrease in the liver volume or serum level of aminotransferases, increased level of bilirubin, severe coagulopathy (high International Normalized Ratio, INR, and decreased level of coagulation factors V and VII). Moreover, alpha-fetoprotein (AFP), serum phosphate, serum lactate, ammonia, vitamin D-binding protein were identified as possible prognostic factors in ALF [3,15,22-27].

There is no predictive model universally accepted for evaluating ALF outcomes in children [1,28], and all are based upon data and experiences in adults [10]. In adults, the most used models are the King's College Criteria (KCC), Clichy criteria, Model for End-stage Liver Disease (MELD), and Wilson index for predicting mortality in WD. The Pediatric End-stage Liver disease (PELD) model was evaluated in children. Models used in Intensive Care Units (ICU) were also analyzed $[1,29,30]$. There is an urgent need for further research in a dynamic scoring system that should include etiology and age [1]. Prompt referral to a transplant center is crucial for those with high risk, and ideally, the prognostic scores should be based on easy to obtain biochemical parameters and clinical features [8]. An ideal predictive model in ALF will help us to be sure that all children needing an LT will receive it (higher sensitivity and positive predictive value, PPV), and those who would survive without LT would not have it (higher specificity and negative predictive value, NPV) $[1,19,31]$.

Our study aimed to analyze PELD/MELD scores and KCC's role in predicting the survival with native liver in children with ALF of different etiologies. Moreover, we analyzed the Nazer prognostic index and Wilson index for predicting mortality performance in WD patients.

\section{Materials and Methods}

We analyzed retrospectively the children ( 0 to 18 years of age) hospitalized for ALF in the two leading children's hospitals in ALF management in Romania (Emergency Clinical Hospital for Children Cluj-Napoca and Grigore Alexandrescu Emergency Clinical Hospital for Children Bucharest), between 2012 and 2018. There were 161 children diagnosed with 
ALF whose medical charts were analyzed, recording their demographic data, and clinical and laboratory parameters.

The study was conducted according to the guidelines of the Declaration of Helsinki, and it was approved by the Ethics Committee. Informed consent was obtained from all subjects involved in the study.

The diagnosis of ALF followed the PALF study group criteria: biochemical evidence of acute liver injury, hepatic-based coagulopathy (prothrombin time, PT > 15 s, INR > 1.5 not corrected by vitamin $\mathrm{K}$ in the presence of $\mathrm{HE}$; or PT $>20 \mathrm{~s}$ or INR $>2.0$ regardless the presence of $\mathrm{HE}$ ) in a patient with no evidence of previous chronic liver disease [10].

Our patients were analyzed function to ALF evolution: poor outcome, defined as LT or death, and good outcomes, defined as long-term survival with native liver (no LT). Based on the age, we grouped our cohort in neonates and infants (under 12-month-old), children (1-12-year-old), and teenagers (12-18-year-old).

We included all patients under 18 years of age, with ALF diagnosis based on PALF criteria, and complete clinical and laboratory data. We excluded the patients that did not fulfill PALF criteria and those without all data needed for MELD or PELD scores calculation or KCC evaluation. We also excluded the patients with ALF due to acute infection with HAV or hepatitis E virus (HEV) hospitalized at Infectious Disease Hospitals based on local epidemiological rules and patients with ALF in multiple systems organ failure (MSOF), trauma, burns, or oncological disease after chemotherapy.

We collected the following data from the patients' medical charts: demographic data (age, sex), ALF etiology (infectious, metabolic, toxic-mushroom poisoning or drug-induced, autoimmune, and unidentified), and laboratory results from the first day of hospitalization (alanine aminotransferase, ALT, aspartate aminotransferase, AST, total bilirubin, TB and direct bilirubin, DB, PT, INR, serum albumin, sodium, creatinine, white blood cells, WBC, hemoglobin, and platelets). For the etiology of ALF, we have used the laboratory tests according to the diagnostic protocols. In ALF due to infections, we analyzed AgHBs for HBV, specific antibodies or viral load for hepatitis $\mathrm{C}$ virus (HCV), Cytomegalovirus (CMV), Epstein-Barr virus (EBV), HSV or enteroviral infection, specific antibodies for Leptospira, inflammation markers (erythrocyte sedimentation rate, ESR, C reactive protein, $\mathrm{CRP}$, and procalcitonin), and blood cultures for bacterial infections. In the metabolic causes of ALF, we analyzed specific enzyme tests, serum amino acids, urinary organic acids, and serum or urinary metabolites evaluated by Nuclear Magnetic Resonance (NMR) spectroscopy [32,33]-galactose, galactitol, tyrosine, and succinyl-acetone. Moreover, genetic tests or histopathologic exams were used to diagnose inborn errors of metabolism (IEM). We have assessed the serum ceruloplasmin and copper level and the $24 \mathrm{~h}$ urinary copper excretion for WD diagnosis. For autoimmune etiology of ALF, we analyzed immunologic tests: serum level of IgG, antinuclear antibodies (ANA, $\geq 1: 40$ ), anti-smooth muscle antibodies (anti-SMA, $\geq 1: 20$ ), anti-soluble liver antigen antibodies (anti-SLA), anti-liver kidney microsomal type 1 (anti-LKM-1, $\geq 1: 20$ ), or anti-liver cytosol antibodies (anti-LC1). The toxic-induced liver injury was diagnosed based on a mushroom or drug ingestion's positive history after other ALF causes were excluded or using urinary or blood toxicology exams.

For every patient, we calculated PELD (in children under 12 years old), MELD, and MELD-Na score (in teenagers) on the first day (admission day), using an online calculator (https: / / www.mdcalc.com, last accessed 12 December 2021), based on formulas previously described: PELD = 0.436 (age $(<1$ year) $)-0.687 \log ($ serum albumin $\mathrm{g} / \mathrm{dL})+0.480 \times 1 \mathrm{log}$ $(\mathrm{TB} \mathrm{mg} / \mathrm{dL})+1.857 \log (\mathrm{INR})+0.667$ (growth retardation $(<-2 \mathrm{SD}))$ [34], MELD $=3.78 \times$ $\log [\mathrm{TB}(\mathrm{mg} / \mathrm{dL})]+11.2 \times \log [\mathrm{INR}]+9.57 \times \log [$ serum creatinine $(\mathrm{mg} / \mathrm{dL})]+6.43$ [35]. To calculate the MELD-Na score, we used the formula: MELD-Na = MELD $-\mathrm{Na}-[0.025 \times$ MELD $\times(140$-serum Na) $]+140$ [36].

Moreover, we evaluated the fulfillment of KCC based on clinical and laboratory data from the first day of hospitalization. In ALF after paracetamol ingestion, an arterial $\mathrm{pH}<7.30$ after bolus infusion or PT $>100 \mathrm{~s}(\mathrm{INR}>6.5)$ and creatinine level over $3.5 \mathrm{mg} / \mathrm{dL}$ and grade III or IV HE is associated with an indication of LT. In ALF with other causes 
(non-paracetamol), PT > $100 \mathrm{~s}$ (INR > 6.5) or three of the following criteria (non-AB viral hepatitis, toxic or unknown cause, more than 7 days from the onset of jaundice to the start of the HE, age under 7 years or over 40 years, PT $>50$ s, INR $>3.5$ or TB $>17.4 \mathrm{mg} / \mathrm{dL}$ ) are associated with an indication of LT [37].

For nine patients with ALF presentation in WD, we calculated the Nazer prognostic index and Wilson index for predicting mortality on the first day of hospitalization. The Nazer index is calculated based on the serum level of AST, bilirubin, and PT and a value of 7 points or higher indicates the need for LT for survival [38]. The Wilson index for predicting mortality is based on the serum level of TB, INR, AST, albumin, and WBC. A cut-off score of 11 points was identified for death without LT [39].

Our analysis did not include the data from the following days of hospitalization as many patients received fresh frozen plasma during their ALF management, and the scores could be biased by this or other treatments received.

We included all data in a Microsoft Office Excel database. For the statistical analysis, we used Statistica version 13 (TIBCO Software Inc., Palo Alto, CA, USA, 2018). We have used descriptive statistics for continuous distribution variables (means and standard deviations) and categorical variables (frequencies and percentages). We have used the t-Student test, Mann-Whitney test (for PELD, MELD, and MELD-Na scores), and Pearson Chi-square (for correlation between qualitative variables). We have calculated the sensitivity, specificity, PPV, NPV, and accuracy for KCC criteria and PELD, MELD, and MELD-Na scores. Discrimination, a model's ability to distinguish patients with different disease outcomes, was assessed using the receiver operating characteristic (ROC) curves. We calculated the area under ROC curve (AUROC) values, confidence intervals, and cut-off values for PELD, MELD, MELD-Na scores, INR, and TB. We used the EasyROC software available online [40]. We selected the cut-off values using the Youden Index, the maximum potential effectiveness index for a test's ability to classify a disease's outcome. With an AUROC over 0.7, the test is considered clinically useful, and an AUROC over 0.8 is considered excellent diagnostic accuracy. However, the test does not correctly predict the outcome for $20 \%$ of cases in the last situation [21]. We analyzed the performance of PELD, MELD, MELD-Na scores, and KCC in predicting the outcome of ALF function to the age of the patients and ALF etiology. The results were considered statistically significant at values of $p<0.05$.

\section{Results}

We included 161 children with ALF in the study, aged between 2 weeks and 17 years and 11 months (mean age $7.66 \pm 8.19$ years); 88 females (54.66\%). According to the age groups, there were 42 infants (26.09\%), 67 children (41.61\%), and 52 teenagers (32.30\%).

The etiology of ALF was different by age group and included toxic causes (64 patients, $39.75 \%$, drug-induced in 51 patients, and mushroom poisoning in 13 patients), infectious diseases (41 patients, 25.45\%), metabolic causes (27 patients, 16.77\%: IEM in 18 patients and WD in 9 patients), and autoimmune diseases (15 patients, 9.32\%). In 14 patients (8.69\%), the etiology remained unknown.

A good outcome, as survivors with native liver after supportive treatment, was in 106 patients (65.84\%), and 55 children (34.16\%) had unfavorable evolution (three patients with emergency LT and 52 with fatal outcome, 32.30\%). Emergency LT was performed in two girls with fulminant WD (four days after diagnosis) and one infant with metabolic disease (one week after diagnosis) that otherwise would not survive.

The demographic data, and clinical and laboratory parameters of our patients are presented in Table 1, based on the outcome of ALF. Patients with poor outcomes were younger, presented on their first day of hospitalization with higher bilirubin and INR and lower albumin and hemoglobin. They presented more frequently HE, metabolic acidosis, and kidney injury. 
Table 1. Demographic data, clinical and laboratory parameters, and prognostic scores in children with ALF based on the disease outcome.

\begin{tabular}{|c|c|c|c|}
\hline Variable & $\begin{array}{c}\text { Survivors with } \\
\text { Native Liver under } \\
\text { Medical Treatment } \\
(n=106)\end{array}$ & $\begin{array}{c}\text { Poor Outcome } \\
\text { (LT or Deceased) } \\
(n=55)\end{array}$ & $p$-Value \\
\hline Age (years) & $8.53 \pm 5.91$ & $5.51 \pm 6.43$ & 0.003304 \\
\hline Males $(n, \%)$ & $45(42.45 \%)$ & $28(50.91 \%)$ & 0.30670 \\
\hline AST (UI/L) & $1332.02 \pm 2057.03$ & $1028.38 \pm 1779.19$ & 0.354363 \\
\hline $\operatorname{ALT}(\mathrm{UI} / \mathrm{L})$ & $1051.47 \pm 1305.89$ & $699.35 \pm 1229.77$ & 0.099954 \\
\hline TB (mg/dL) & $4.40 \pm 5.45$ & $9.27 \pm 12.30$ & 0.000663 \\
\hline $\mathrm{DB}(\mathrm{mg} / \mathrm{dL})$ & $3.26 \pm 4.41$ & $7.04 \pm 10.05$ & 0.001158 \\
\hline INR & $2.44 \pm 1.21$ & $3.76 \pm 2.78$ & 0.000046 \\
\hline Albumin (mg/dL) & $3.29 \pm 0.48$ & $2.97 \pm 0.71$ & 0.000732 \\
\hline Hemoglobin (g/dL) & $10.79 \pm 2.26$ & $9.36 \pm 2.34$ & 0.000341 \\
\hline White blood cells $\left(/ \mathrm{mm}^{3}\right)$ & $14422 \pm 21178$ & $14126 \pm 8990$ & 0.921381 \\
\hline Platelets $\left(/ \mathrm{mm}^{3}\right)$ & $198490 \pm 106904$ & $207418 \pm 166127$ & 0.680128 \\
\hline Ceruloplasmin $(\mathrm{mg} / \mathrm{dL}) *$ & $10.175 \pm 5.863$ & $7.75 \pm 4.179$ & 0.52570 \\
\hline Encephalopathy $(n, \%)$ & $17(16.04 \%)$ & $28(50.91 \%)$ & $<0.00001$ \\
\hline Metabolic acidosis $(n, \%)$ & $58(54.72 \%)$ & $40(72.73 \%)$ & 0.02637 \\
\hline Acute kidney injury $(n, \%)$ & $13(12.26 \%)$ & $27(49.09 \%)$ & $<0.00001$ \\
\hline Renal replacement $(n, \%)$ & $11(10.38 \%)$ & $10(18.18 \%)$ & 0.16317 \\
\hline $\operatorname{PELD}(n=109)$ & $13.99 \pm 10.07$ & $21.04 \pm 13.28$ & 0.002282 \\
\hline $\operatorname{MELD}(n=52)$ & $19.51 \pm 8.57$ & $36.20 \pm 13.44$ & 0.000002 \\
\hline MELD-Na $(n=52)$ & $20.08 \pm 8.47$ & $33.07 \pm 8.29$ & 0.000006 \\
\hline $\operatorname{KCC}(n, \%)$ & $6(5.66 \%)$ & $16(29.09 \%)$ & 0.0004 \\
\hline
\end{tabular}

LT-liver transplantation; AST—aspartate aminotransferase; ALT—alanine aminotransferase; TB-total bilirubin DB_-direct bilirubin; INR_-International normalized ratio; PELD_Pediatric End-Stage Liver Disease; MELD_Model for End-Stage Liver Disease; MELD-Na-Model for End-Stage Liver Disease including sodium level KCC-King's College Criteria. Continuous parameters are represented as mean \pm standard deviation and categorical parameters as number and percentage. ${ }^{*}$ Serum level of ceruloplasmin was evaluated only for patients with Wilson's Disease.

The PELD score was calculated for 109 patients with age under 12 years, and the mean value was $16.58 \pm 11.80$. For 52 patients between 12 and 18 years, the MELD and MELD-Na score was calculated, and the mean value was $24.33 \pm 12.64$ and $23.84 \pm 10.24$, respectively. The PELD score was significantly higher $(21.04 \pm 13.28)$ in patients with poor outcomes than survivors $(13.99 \pm 8.57 ; p=0.002282)$. The teenagers with unfavorable evolution had a higher MELD and MELD-Na score than survivors with native liver $(36.20 \pm 13.44$ and $33.07 \pm 8.29$ vs. $19.51 \pm 8.57$ and $20.08 \pm 8.47 ; p<0.00001)$.

The PELD score in neonates and infants did not differ based on the ALF evolution: $21.99 \pm 14.50$ in those with poor outcomes vs. $19.07 \pm 12.72(p=0.474096)$ in survivors. However, in children aged 1 to 12 years, the PELD score was significantly higher in those with poor outcomes (19.62 \pm 11.52 vs. $11.61 \pm 7.61, p=0.002415)$.

In Table 2, the PELD, MELD, and MELD-Na scores in different causes of ALF are presented based on the outcomes. In toxic causes, WD, and ALF's unknown causes, these scores were significantly higher in patients with poor outcomes. There was no difference for infectious, IEM, or autoimmune causes of ALF. 
Table 2. The PELD, MELD, MELD-Na scores function to the etiology of acute liver failure.

\begin{tabular}{|c|c|c|c|}
\hline & $\begin{array}{c}\text { Survivors with } \\
\text { Native Liver under } \\
\text { Medical Treatment }\end{array}$ & $\begin{array}{l}\text { Poor Outcome } \\
\text { (LT or Deceased) }\end{array}$ & $p$-Value \\
\hline \multicolumn{4}{|c|}{ Toxic causes } \\
\hline PELD & $9.90 \pm 7.16$ & $25.32 \pm 17.16$ & 0.003192 \\
\hline MELD & $18.36 \pm 9.09$ & $37.28 \pm 10.73$ & 0.000037 \\
\hline MELD-Na & $18.82 \pm 8.96$ & $34.28 \pm 6.02$ & 0.000142 \\
\hline \multicolumn{4}{|c|}{ Infectious causes } \\
\hline PELD & $13.63 \pm 7.80$ & $15.52 \pm 9.61$ & 0.546069 \\
\hline MELD & $17 \pm 4.24$ & $26 \pm 0$ & 0.333333 \\
\hline MELD-Na & $21 \pm 7.07$ & $26 \pm 0$ & 0.666667 \\
\hline \multicolumn{4}{|c|}{ Autoimmune causes } \\
\hline PELD & $15.06 \pm 6.12$ & $14.50 \pm 0$ & 0.9333 \\
\hline MELD & $23.50 \pm 6.89$ & & \\
\hline MELD-Na & $24.17 \pm 6.55$ & & \\
\hline \multicolumn{4}{|c|}{ Metabolic causes } \\
\hline IEM-PELD & $31.92 \pm 14.06$ & $25.90 \pm 16.92$ & 0.491631 \\
\hline WD-MELD & $20 \pm 0$ & $45.80 \pm 8.93$ & 0.057692 \\
\hline WD-MELD-Na & $21 \pm 0$ & $39 \pm 2.24$ & 0.001826 \\
\hline \multicolumn{4}{|c|}{ Unknown etiology } \\
\hline PELD & $5.467 \pm 1.955$ & $23.544 \pm 8.898$ & 0.006922 \\
\hline MELD & $21 \pm 0$ & $19 \pm 0$ & \\
\hline MELD-Na & $24 \pm 0$ & $19 \pm 0$ & \\
\hline
\end{tabular}

PELD—Pediatric End-Stage Liver Disease; MELD—Model for End-Stage Liver Disease; MELD-Na—Model for End-Stage Liver Disease including sodium level; LT—liver transplantation, IEM—inborn errors of metabolism; WD-Wilson's disease.

We analyzed the performance of the MELD and MELD-Na scores compared to INR and TB serum levels in discriminating the teenagers with poor outcomes from the survivors using ROC curves (Figure 1a,b). In teenagers, INR (using a cut-off of 3) had an AUROC of 0.7946, TB (cut-off $2.3 \mathrm{mg} / \mathrm{dL}$ ) had an AUROC of 0.7991, but MELD and MELD-Na score (both at a cut-off of 28) performed better with AUROC 0.8495 and 0.8576 , respectively. In those with toxic causes, MELD and MELD-Na scores predict the fatal outcome better but at a lower cut-off (Table 3).

In children up to 12 years old, the PELD score performed lower (AUROC 0.6686) than the MELD score in teenagers, but better than INR or TB in predicting the fatal outcome in ALF. If we excluded the neonates and infants, the PELD score has better performance (AUROC 0.7181), but also INR over $3 \mathrm{mg} / \mathrm{dL}$ performed well (AUROC 0.7335) (Table 3 and Figure $1 \mathrm{c}, \mathrm{d})$. In neonates and infants, PELD score, INR and TB had a low accuracy with an AUROC under or close to 0.6 (Table 3).

In our cohort, KCC proved to have a sensibility of $29.09 \%$, specificity of $94.34 \%$, PPV of $72.73 \%$, and NPV of $71.95 \%$. The accuracy was $72.05 \%$. If we analyzed the KCC criteria in children over one year of age (as analyzed in the original cohort for KCC), the performance increased: sensibility of $32.26 \%$, specificity of $98.81 \%$, PPV of $90.91 \%$, NPV of $79.17 \%$, and accuracy of $80.87 \%$. The best performance was in teenagers with a specificity of $100 \%$, PPV of $100 \%$, NPV of $82.22 \%$, and accuracy of $84.61 \%$ (Table 3). 


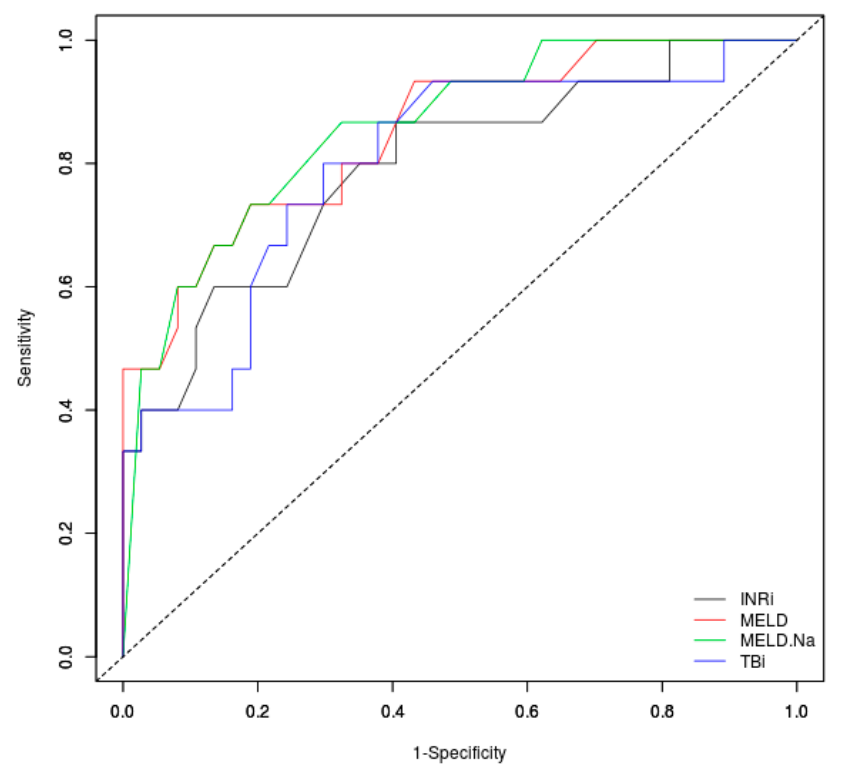

(a)

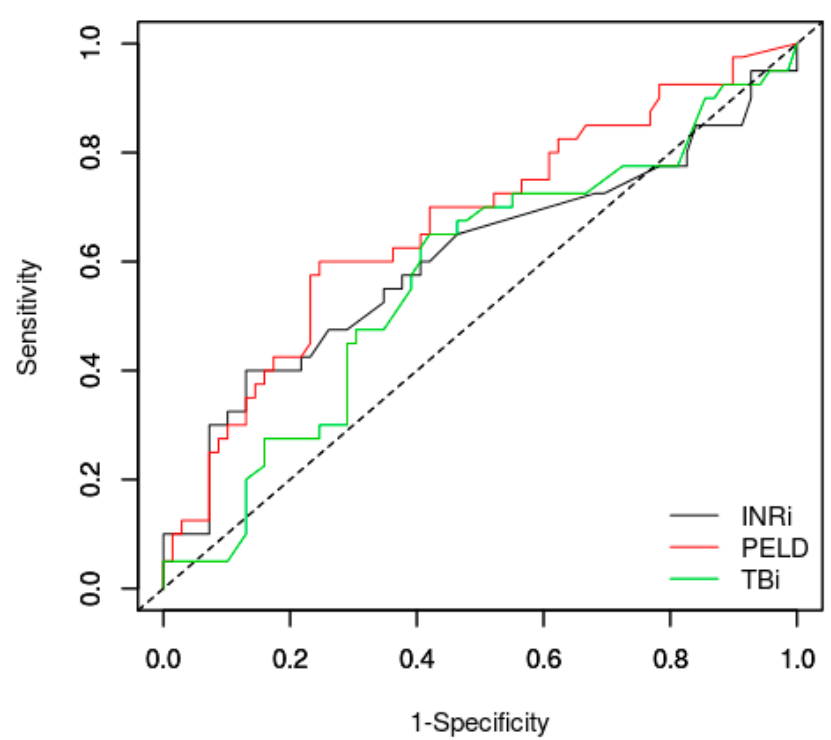

(c)

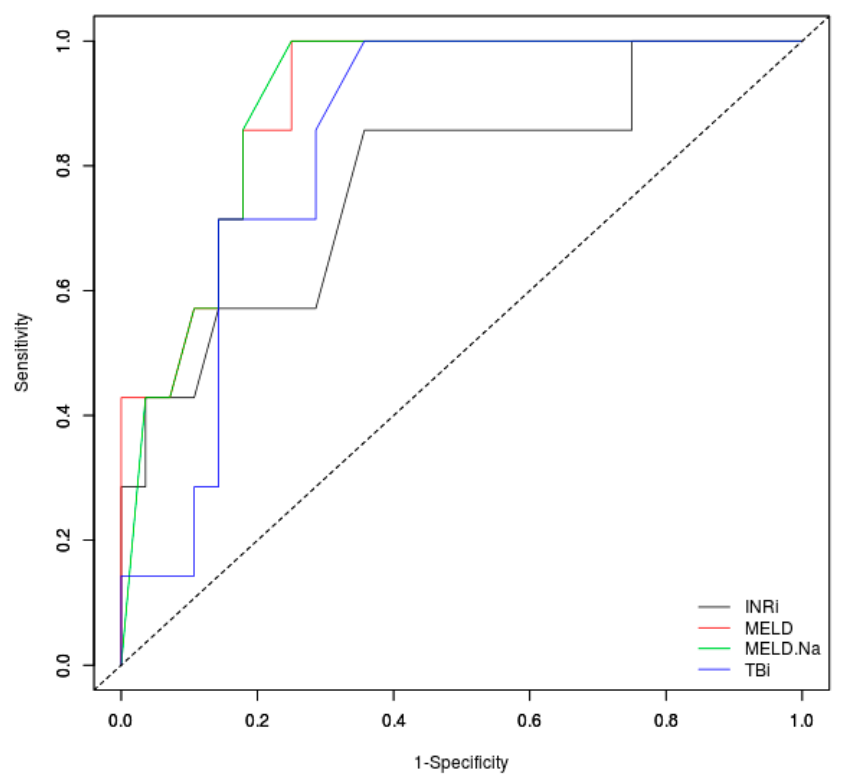

(b)

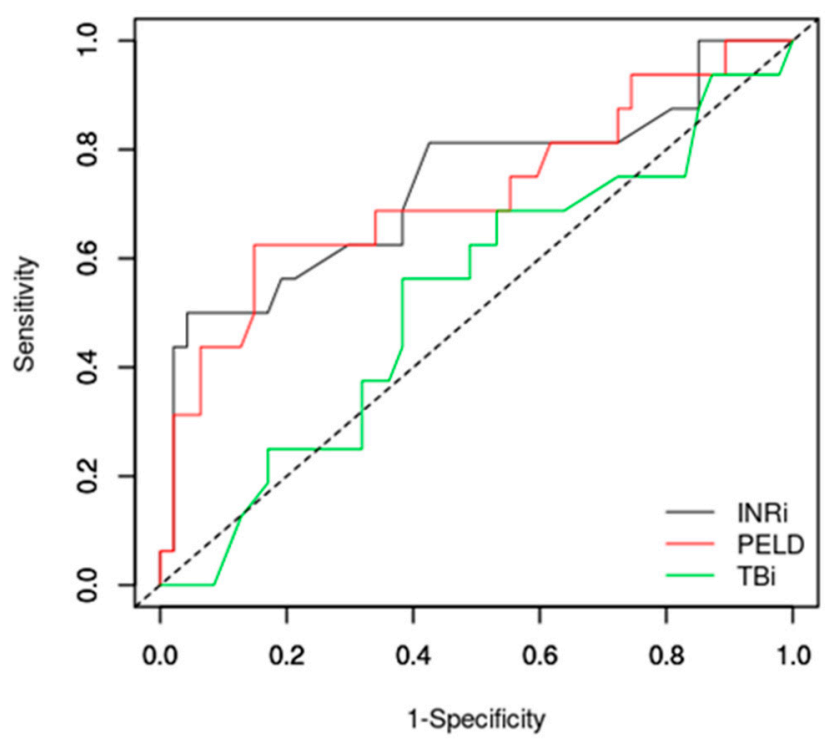

(d)

Figure 1. ROC curves in predicting the fatal outcome in ALF: teenagers (a), toxic causes (b), children up to 12 years old (c) and children from one to 12 years (infants and neonates excluded) (d). MELD - Model for End-Stage Liver Disease; MELD-Na-Model for End-Stage Liver Disease including sodium level; PELD—Pediatric End-Stage Liver Disease; INR-International Normalized Ratio; TB-total bilirubin.

Analyzing KCC for the patients with toxic ALF (64 children), 4 patients with fatal evolution and no survivors had positive KCC, but 7 patients with poor outcomes did not fulfill the KCC. In children with metabolic diseases (27 patients), 8 children with fatal evolution and 3 survivors had positive KCC. Yet, there were 10 patients with unfavorable evolution without having KCC. In ALF after infections (41 patients), none of those 15 patients with fatal outcomes had positive KCC. At the same time, these criteria were present in three survivors. In patients with ALF due to autoimmune diseases (15 patients), only one patient died without positive KCC. Ten children with ALF of unknown cause had a fatal evolution, and only four had positive KCC. Those four who survived with native liver were without 
positive KCC. Based on all these data, KCC proved to have a specificity between $66.67 \%$ in metabolic ALF and 100\% in toxic, autoimmune, and unknown causes. Overall, KCC had the best performance in toxic causes of ALF (Table 3).

Table 3. Performances of MELD, MELD-Na, and PELD scores, INR, TB serum level, and KCC in predicting the fatal outcome in ALF.

\begin{tabular}{|c|c|c|c|c|c|c|}
\hline Parameter & Cut-Off & Sensitivity & Specificity & PPV & NPV & AUROC \\
\hline \multicolumn{7}{|c|}{ Teenagers $(n=52)$} \\
\hline INR & 3 & $60 \%$ & $86.5 \%$ & $64.3 \%$ & $84.2 \%$ & 0.7946 \\
\hline TB & $2.3 \mathrm{mg} / \mathrm{dL}$ & $80 \%$ & $70.3 \%$ & $52.2 \%$ & $89.7 \%$ & 0.7991 \\
\hline MELD & 28 & $73.3 \%$ & $81.1 \%$ & $61.1 \%$ & $88.2 \%$ & 0.8495 \\
\hline MELD-Na & 28 & $73.3 \%$ & $81.1 \%$ & $61.1 \%$ & $88.2 \%$ & 0.8576 \\
\hline \multicolumn{7}{|c|}{ Teenagers with ALF of toxic causes $(n=35)$} \\
\hline INR & 2.5 & $85.7 \%$ & $64.3 \%$ & $37.5 \%$ & $94.7 \%$ & 0.7781 \\
\hline TB & $1.3 \mathrm{mg} / \mathrm{dL}$ & $100 \%$ & $64.3 \%$ & $41.2 \%$ & $100 \%$ & 0.8367 \\
\hline MELD & 24 & $100 \%$ & $75 \%$ & $50 \%$ & $100 \%$ & 0.9056 \\
\hline MELD-Na & 26 & $100 \%$ & $75 \%$ & $50 \%$ & $100 \%$ & 0.9031 \\
\hline \multicolumn{7}{|c|}{ Children under 12 years old $(n=109)$} \\
\hline INR & 3 & $40 \%$ & $87 \%$ & $64 \%$ & $71.4 \%$ & 0.6045 \\
\hline ТВ & $3.4 \mathrm{mg} / \mathrm{dL}$ & $65 \%$ & $58 \%$ & $47.3 \%$ & $74.1 \%$ & 0.5725 \\
\hline PELD & 18.9 & $60 \%$ & $75.4 \%$ & $58.5 \%$ & $76.5 \%$ & 0.6686 \\
\hline \multicolumn{7}{|c|}{ Children under 12 years old-excluding neonates and infants $(n=63)$} \\
\hline INR & 3 & $50 \%$ & $95.7 \%$ & $80 \%$ & $84.9 \%$ & 0.7334 \\
\hline TB & $4 \mathrm{mg} / \mathrm{dL}$ & $56.2 \%$ & $61.7 \%$ & $33.3 \%$ & $80.6 \%$ & 0.5286 \\
\hline PELD & 19.5 & $62.5 \%$ & $85.1 \%$ & $58.8 \%$ & $87 \%$ & 0.7181 \\
\hline \multicolumn{7}{|c|}{ Neonates and infants $(n=46)$} \\
\hline INR & 10 & $12.5 \%$ & $100 \%$ & $100 \%$ & $51.2 \%$ & 0.4896 \\
\hline ТВ & $6.6 \mathrm{mg} / \mathrm{dL}$ & $54.2 \%$ & $77.3 \%$ & $72.2 \%$ & $60.7 \%$ & 0.6146 \\
\hline PELD & 12.9 & $75 \%$ & $40.9 \%$ & $58.1 \%$ & $60 \%$ & 0.5511 \\
\hline & & & & & & Accuracy \\
\hline \multicolumn{7}{|c|}{ KCC based on age } \\
\hline Neonates and & its $(n=46)$ & $25.00 \%$ & $77.27 \%$ & $54.55 \%$ & $48.57 \%$ & $50 \%$ \\
\hline Childre & = 63) & $18.75 \%$ & $97.87 \%$ & $75 \%$ & $77.97 \%$ & $77.78 \%$ \\
\hline Teenage & $=52)$ & $46.67 \%$ & $100 \%$ & $100 \%$ & $82.22 \%$ & $84.61 \%$ \\
\hline \multicolumn{7}{|c|}{ KCC based on ALF etiology } \\
\hline Toxic cau & $=64)$ & $36.36 \%$ & $100 \%$ & $100 \%$ & $88.33 \%$ & $89.06 \%$ \\
\hline Metabo & $=27)$ & $44.44 \%$ & $66.67 \%$ & $72.73 \%$ & $37.50 \%$ & $51.85 \%$ \\
\hline Infectio & $=41)$ & $0 \%$ & $88.46 \%$ & $0 \%$ & $60.53 \%$ & $56.10 \%$ \\
\hline Autoimm & $n=15)$ & $0 \%$ & $100 \%$ & $0 \%$ & $93.33 \%$ & $93.33 \%$ \\
\hline Unknov & $=14)$ & $40 \%$ & $100 \%$ & $100 \%$ & $40 \%$ & $57.14 \%$ \\
\hline
\end{tabular}

MELD-Model for End-Stage Liver Disease; MELD-Na-Model for End-Stage Liver Disease including sodium level; PELD—Pediatric End-Stage Liver Disease; INR—International Normalized Ratio; TB—total bilirubin; KKC-King's College Criteria; PPV—-positive predictive value; NPV—negative predictive value; AUROC—Area Under the Receiver Operating Characteristic.

In those nine children with WD, we calculated the Nazer prognostic index and Wilson index for predicting mortality [38,39]. Six patients scored seven or higher for Nazer prognostic score: five teenagers with unfavorable evolution of ALF (two girls with emergency LT and three who did not survive) and one child who survived. The other three survivors scored under seven. Based on these data, the accuracy of Nazer score for predicting the unfavorable outcome was $88.9 \%$, with a sensitivity of $100 \%$, specificity of $75 \%$, PPV of $83.3 \%$, and NPV of $100 \%$. Regarding the Wilson index for predicting mortality, 5 patients scored over 11 , all with unfavorable evolution. Based on these data, the accuracy of the Wilson index was $100 \%$, with a sensitivity, specificity, PPV, and NPV of $100 \%$, proving to be better than the previously used Nazer prognostic index. In WD patients, MELD/PELD scores were higher in patients with poor outcomes $(45.80 \pm 8.93$ vs. $13.37 \pm 6.20, p=0.000473)$. Those with unfavorable outcome were with higher serum level of TB $(32.90 \pm 18.30 \mathrm{mg} / \mathrm{dL}$ vs. $1.73 \pm 0.86 \mathrm{mg} / \mathrm{dL}, p=0.012), \mathrm{DB}(27.36 \pm 16.05 \mathrm{mg} / \mathrm{dL}$ vs. $1.33 \pm 0.57 \mathrm{mg} / \mathrm{dL}, p=0.015)$, INR $(6.14 \pm 2.83$ vs. $2.62 \pm 0.58, p=0.046)$, and lower albumin level $(2.58 \pm 0.52 \mathrm{~g} / \mathrm{dL}$ 
vs. $3.43 \pm 0.17 \mathrm{~g} / \mathrm{dL}, p=0.017)$. There were no significant differences in serum level of transaminases, ceruloplasmin, or hemoglobin in those with poor outcomes than survivors. Analyzing KCC only in WD patients, from five with unfavorable outcomes, four had KCC. None of the survivors had positive KCC. Considering the small number of patients, the specificity of KCC was $100 \%$, sensitivity $80 \%$, PPV $100 \%$, NPV $80 \%$, and the accuracy was $88.9 \%$.

\section{Discussion}

ALF is rare in children but is characterized by a high severity and risk for a fatal outcome if proper treatment or sometimes emergency LT is impossible. It is essential in such cases to have accurate predictive tools to discriminate patients with high risk to include them early on the emergency LT list and identify those that will recover spontaneously or with proper specific treatment $[3,19,41]$.

In adults, many parameters were evaluated for their prognostic value in ALF: peak TB level [17,42,43], transaminases [8,9,42], INR or PT [9,17,43-45], presence of grade III/IV $\mathrm{HE}[1,29,43-45]$, more than seven days to the onset of $\mathrm{HE}[9,45]$, age $[8,17,45]$, serum creatinine [45], thrombocytopenia as a marker of multiple organ failure [3,46], high ammonia $[8,17,26,27]$, high plasma lactate $[17,47]$, actin-free Gc globulin $[26,48-52]$, and serum phosphate $[26,53,54]$. Galectine- 9 as a marker of liver injury was evaluated as a prognostic factor in DILI [55]. Other new parameters studied in adults with ALF were IL6, IL10, IL8, soluble CD154, and apoptosis marker M30 of the cytokeratin $18[1,17,54,56]$. The most important problem regarding these parameters is the lack of availability of these measurements in any hospital and the need for quick results to help an early decision.

Studies on different clinical and laboratory parameters in ALF in children found that high TB level [3,44,57], increased INR [1,3,44,57], lower transaminases [58], young age $[12,57,59]$, and encephalopathy $[3,44,57]$ are prognostic factors for those who will need LT. Our team recently published a study on the role of Gc-globulin as a prognostic marker in children with ALF [25].

There are many predictive models on the need for LT in ALF, but none is universally accepted in adults and children [28]. The ideal predictive model should be based on standard clinical and laboratory parameters, easy to measure in any hospital, and dynamic analysis. Data on a particular moment may have a limited value, and the risk should be evaluated during disease evolution $[21,31,58,60,61]$. Predictive models need to be studied further as improvements should be made to consider the severity of liver necrosis and the possibility of liver regeneration [26]. Moreover, they need to include the age and etiology of ALF [1,62].

The MELD and PELD scores were designed to assess the risk of mortality and need of LT in chronic liver disease, but their usefulness in ALF was assessed more and more in the last years $[1,45,63]$.

KCC are used for evaluating the need for LT in ALF. Their presence predicts mortality without LT, but their absence is not necessarily associated with survival $[18,64]$. KCC are used mainly in adults and were not validated in children [37]. KCC may differ in accuracy in children than adults as HE is challenging to assess, and the etiology may be different or even unknown in many children. Moreover, in the original study, none of those 29 children included were under 1 year [37]. KCC may not successfully allow a correct decision for LT as sometimes predict the need of LT in more children than they would need $[62,65]$.

Based on age, HE, and serum level of factor $\mathrm{V}$, Clichy criteria proved low sensitivity [24]. It was reported to have a PPV of 0.82 and NPV of 0.98 , but the cohort was made of adults with fulminant HBV, so it is difficult to generalize these results [21]. We did not evaluate Clichy criteria in our cohort, as we did not have data regarding the factor V level for all subjects.

Our study aimed to analyze the possible role of PELD, MELD scores, and KCC in a large cohort of children with ALF from two important hospitals in our country. Our cohort is uniformly distributed on age and includes patients with various causes of ALF (toxic, 
infections, autoimmune disorders, and metabolic diseases). We considered the LT patients as unfavorable outcomes because they probably would not survive without LT. One of the problems in all modeling is the end-point. All models have limitations as all studies suggest that TB, INR, and HE may predict poor outcomes. If the decision to perform LT is based on these factors, the results of the predicting models may be biased [61]. As Schneider et al. commented, if LT is excluded from the analysis, the PELD score could not be significant in predicting poor outcomes [16]. In our study, only three patients were with emergency LT.

The PELD and MELD scores should be used cautiously in ALF in children as there is a high heterogeneity with various etiologies, different ages. Moreover, in adults, there is a problem regarding the characteristics of hyperacute patients (associated with a good chance for spontaneously recovering, even with high INR and encephalopathy) and subacute patients (associated with poor prognosis) [31]. The PELD score was validated for the need for LT in chronic diseases to predict 3-month pretransplant mortality [3,66]. It includes growth failure and serum albumin level that are not usually associated with ALF [3].

The PELD score at different cut-offs was studied and proved to have better sensitivity and specificity than TB, INR, or HE in predicting poor outcomes in ALF. Sanchez and D'Agostino reported that, at a cut-off of 33, the PELD score had a better sensitivity and specificity than KCC in a cohort of 40 children, most of them with HAV infection [12]. Other studies found significant a lower cut-off for PELD, at 27 or 28 [58,67].

Yantorno et al. [68] reported that a MELD score over 30 is superior to KCC and Clichy, with a PPV of $91 \%$ and an NPV of $100 \%$. In this study, the adolescents were excluded. Many meta-analyses were published assessing the performance of MELD score and KCC in ALF in adults. Based on 23 studies, including 2153 patients [69], MELD score and KCC proved to be comparable in accuracy, but KCC has a lower sensitivity and MELD has a lower specificity. The presence of HE, subjectively included in KCC, weakens the performance of KCC compared to MELD [69]. Another meta-analysis assessed KCC in non-acetaminophen and proved the higher specificity of KCC [61]. A systematic review based on 14 studies calculated for KCC a specificity of $94.6 \%$, with lower sensitivity (58\%) and an AUC of 0.91 [54]. Based on etiology, KCC had a 70-88\% diagnostic accuracy in acetaminopheninduced ALF and 55 to $92 \%$ in non-acetaminophen ALF [26]. In non-acetaminophen ALF, up to $70 \%$ died without KCC, and $21 \%$ of those with KCC would survive without LT [26]. In a cohort of 522 children with non-paracetamol ALF, the KCC had a lower sensitivity than in adults with similar specificity [37].

In our study, the MELD score, at a cut-off of 28, proved to have an $81.1 \%$ specificity and 73.3\% sensitivity, similar to that reported by Sanchez, D'Agostino [12] and Yantorno [68], and better than the admission day results reported by Rajanayagam [58]. Using the peak values in Rajanayagam's study [58], the MELD score had similar results as in our study. We did not analyze the dynamic of scores during evolution, but this would be the best approach if some treatment effects were considered. It was proved that serial determination of scores is superior to a single measurement at admission $[58,60]$.

Analyzing the performance of the MELD score by diagnosis for toxic causes of ALF, we proved that the MELD score at admission is an excellent predictor of poor outcome, having excellent sensitivity but lower specificity.

In our cohort, in children under 12 years, the PELD score performed lower. Excluding the infants, the performance increased, but remained lower than the MELD score. Interestingly, INR > 3 was a slightly better predictor of poor outcome than the PELD score in this subgroup of patients.

In our study, KCC demonstrates a high specificity but lower sensitivity, as was described in a previously published meta-analysis [54,61,69]. The accuracy was not as high as in adult studies. If we excluded the infants from the analysis, the performance of KCC improved. In our cohort, the best performance of KCC was shown in teenagers.

$\mathrm{HE}$ is an important prognostic factor in adults (included in KCC or Clichy criteria, but not in the MELD score). However, it is challenging to diagnose HE in children, and it could be rapidly progressive [1]. In the PALF study group, mortality was higher in children 
presenting with grade III and IV HE or rapid progression after admission [70]. In our study, the patients with poor outcomes presented on admission day more frequently HE than the survivors. Moreover, metabolic acidosis and acute kidney injury were more frequent in children with unfavorable outcomes.

Studies have tried to improve the MELD score and KCC by adding other parameters. However, including the lactate and phosphate level did not bring a clear advantage, for although the sensitivity of KCC was improved, the specificity was reduced [53,71]. Adding serum sodium to the MELD score increased the predictive value [36]; however, there were no significant differences in our study when the MELD-Na score was calculated.

There are more criteria to predict the fatal outcome in ALF due to mushroom poisoning, but none are universally accepted [72]. Besides KCC, Ganzert's (a decrease in prothrombin index under $25 \%$ of normal between the 3rd and 10th day after ingestion associated with a serum creatinine over $1.2 \mathrm{mg} / \mathrm{dL}$ ) [73] and Escudie's criteria (interval between ingestion and diarrhea under $8 \mathrm{~h}$ or a decrease in prothrombin index under $10 \%$ of normal, INR $>6$, at four or more days after ingestion) [74] have also proved to be helpful in ALF due to mushroom poisoning. Ganzert proved that the prothrombin index and serum creatinine were significantly better predictors than serum bilirubin and ALT [73]. In our previous works, in children mostly with ALF due to mushroom poisoning, serum creatinine and HE presence were found to predict mortality independently [75]. Moreover, in a study including 17 children with ALF due to mushroom poisoning, a PELD score over 20 had a $100 \%$ sensitivity and specificity to predict the fatal outcome, slightly better than KCC's $77.7 \%$ sensitivity and $100 \%$ specificity [76]. The present study, including a larger cohort of pediatric ALF patients, did not analyze mushroom poisoning separately because the number of patients with this cause of ALF decreased in the last years in our country [77]. Instead, we analyzed all toxic causes of ALF in 64 patients. The MELD score (at a cut-off of 24) had an excellent power of discrimination. The MELD score performed better than INR over 2.5 or TB. Moreover, in children under 12 years old, the PELD score was significantly higher in those with fatal outcomes than in survivors. KCC performed similarly in these patients with $100 \%$ specificity and lower sensitivity. The accuracy of KCC was similar to the MELD score. For other etiologies of ALF in our cohort, KCC had lower accuracy, excepting autoimmune disorders (there was only one case with fatal evolution but without fulfilling the KCC).

The PELD and MELD scores do not consider comorbidities, such as infections and sepsis, which may increase mortality $[60,78]$. Some authors tried to evaluate the ICU scores due to these aspects. Acute Physiology and Chronic Health Evaluation (APACHE II) $[56,79,80]$, Acute Liver Failure Study Group (ALFSG) index [56,81], Sequential Organ Failure Assessment (SOFA) [41,80], pediatric Chronic LIver Failure Sequential Organ Failure Assessment (pCLIF-SOFA) [29], Pediatric RISk of Mortality (PRISM) [30], Pediatric Index of Mortality (PIM) [82], Acute Liver Failure Early Dynamic (ALFED) model [11,83], and Simplified Acute Physiology Score III (SAPS III) $[17,84]$ were analyzed in various studies. Still, the heterogeneity of the cohorts and results make it difficult to support that they are a better predictor than MELD or KCC in ALF patients [30].

LIU (Liver Injury Units) based on peak levels of bilirubin, PT, and ammonia proved to be strongly predictive in ALF in children. LIU, based on admission levels, has moderate predictive strength [20]. LIU may be used daily to predict the possible outcome anytime during hospitalization [85].

In WD patients, the Wilson index for predicting mortality could predict very well the need for an emergency LT $[38,86]$. In our study, the accuracy, sensitivity, and specificity were $100 \%$, better than the Nazer prognostic index performance. Moreover, KCC had a specificity of $100 \%$, but a lower accuracy. The MELD/PELD score was higher in those with fatal outcomes (over 30) than survivors (under 20). Our data support the need to evaluate the Wilson index for predicting mortality on the admission day of a child with WD and ALF to early referral to an LT center [86]. 


\section{Conclusions}

ALF is a severe disease in children, and there are clinical and laboratory parameters or scores that can help us predict poor outcomes. Children with unfavorable evolution are younger, and present with higher TB and INR, and lower albumin and hemoglobin. They present HE, metabolic acidosis, and acute kidney injury more frequently than survivors. The PELD and MELD scores, and KCC and Wilson indexes, proved helpful in children with ALF, having a good accuracy in discriminating patients who need emergency LT. The MELD score had the best performance in teenagers with ALF of toxic cause, and the PELD score had a lower performance than the MELD score. The PELD score and KCC had low accuracy for predicting fatal evolution in neonates and infants. KCC had the highest accuracy in teenagers and ALF of toxic causes. The MELD score and KCC had a similar accuracy, but MELD had a higher sensitivity, and KCC a higher specificity. Besides the improvements in supportive measures, mortality in ALF in children was still high, and the emergency LT represents the only hope for some of them. For this reason, finding the best predicting score in ALF, and early referral of the children to a specialized center, are the most critical issues to improve survival.

Author Contributions: Conceptualization, T.L.P. and A.G.; methodology, T.L.P., C.E.U. and A.G.; validation, T.L.P., D.P., C.E.U. and A.G.; formal analysis, T.L.P., A.G., D.B., C.E.U. and D.P.; investigation, T.L.P., C.O.A., D.D., B.B., D.B., D.P., C.E.U. and A.G.; resources, T.L.P., D.P., C.E.U. and A.G.; data curation, T.L.P., C.O.A., D.D., B.B., D.B., D.P., C.E.U. and A.G.; writing-original draft preparation, T.L.P. and A.G.; writing-review and editing, T.L.P.; supervision, T.L.P. and C.E.U. All authors have read and agreed to the published version of the manuscript.

Funding: This research received no external funding.

Institutional Review Board Statement: The study was conducted according to the guidelines of the Declaration of Helsinki and it was approved by the Ethics Committee of Emergency Children Hospital Cluj-Napoca, Romania (41SC/11 January 2016).

Informed Consent Statement: Informed consent was obtained from all subjects involved in the study.

Data Availability Statement: Data are available on request from the corresponding author.

Conflicts of Interest: The authors declare no conflict of interest.

\section{References}

1. Jain, V.; Dhawan, A. Prognostic modeling in pediatric acute liver failure. Liver Transpl. 2016, 22, 1418-1430. [CrossRef]

2. Sokol, J.R.; Narkewicz, R.M. Liver and pancreas. In Current Diagnosis E Treatment Paediatrics, 20th ed.; Hay, W.W., Levin, J.M., Sondheimer, M.J., Deterding, R.R., Eds.; Mc Graw Hill Education: New York, NY, USA, 2011; pp. 631-651.

3. Gilbert Pérez, J.J.; Jordano Moreno, B.; Rodríguez Salas, M. Aetiology, outcomes and prognostic indicators of paediatric acute liver failure. An. Pediatr. (Engl. Ed.) 2018, 88, 63-68. [CrossRef] [PubMed]

4. Devictor, D.; Tissieres, P.; Durand, P.; Chevret, L.; Debray, D. Acute liver failure in neonates, infants and children. Expert Rev. Gastroenterol. Hepatol. 2011, 5, 717-729. [CrossRef] [PubMed]

5. Devictor, D.; Tissieres, P.; Afanetti, M.; Debray, D. Acute liver failure in children. Clin. Res. Hepatol. Gastroenterol. 2011, 35, 430-437. [CrossRef] [PubMed]

6. Grama, A.; Aldea, C.O.; Burac, L.; Delean, D.; Bulata, B.; Sirbe, C.; Duca, E.; Boghitoiu, D.; Coroleuca, A.; Pop, T.L. Etiology and outcome of acute liver failure in children-The experience of a single tertiary care hospital from Romania. Children 2020, 7, 282. [CrossRef] [PubMed]

7. Squires, J.E.; McKiernan, P.; Squires, R.H. Acute liver failure: An update. Clin. Liver Dis. 2018, 22, 773-805. [CrossRef]

8. Kathemann, S.; Bechmann, L.P.; Sowa, J.P.; Manka, P.; Dechêne, A.; Gerner, P.; Lainka, E.; Hoyer, P.F.; Feldstein, A.E.; Canbay, A. Etiology, outcome and prognostic factors of childhood acute liver failure in a German single center. Ann. Hepatol. 2015, 14, 722-728. [CrossRef]

9. Lee, W.S.; McKiernan, P.; Kelly, D.A. Etiology, outcome and prognostic indicators of childhood fulminant hepatic failure in the United Kingdom. J. Pediatr. Gastroenterol. Nutr. 2005, 40, 575-581. [CrossRef]

10. Squires, R.H. Acute liver failure in children. Semin. Liver Dis. 2008, 28, 153-166. [CrossRef]

11. Saluja, V.; Sharma, A.; Pasupuleti, S.S.; Mitra, L.G.; Kumar, G.; Agarwal, P.M. Comparison of prognostic models in acute liver failure: Decision is to be dynamic. Indian J. Crit. Care Med. 2019, 23, 574-581. [CrossRef]

12. Sanchez, M.C.; D'Agostino, D.E. Pediatric end-stage liver disease score in acute liver failure to assess poor prognosis. J. Pediatr. Gastroenterol. Nutr. 2012, 54, 193-196. [CrossRef] 
13. Batra, Y.; Acharya, S.K. Acute liver failure: Prognostic markers. Indian J. Gastroenterol. 2003, 22, $66-86$.

14. Bhatia, V.; Bavdekar, A. Management of acute liver failure in infants and children: Consensus statement of the pediatric gastroenterology chapter, Indian academy of pediatrics. Indian Pediatr. 2013, 50, 477-482. [CrossRef]

15. Whitington, P.F.; Alonso, E.M. Fulminant hepatitis and acute liver failure. In Diseases of the Liver and Biliary System in Children, 2nd ed.; Deirdre, K., Ed.; Wiley-Blackwell: Oxford, UK, 2003; pp. 107-126. [CrossRef]

16. Shneider, B.L. To transplant or not to transplant: Certainly one of the questions. J. Pediatr. Gastroenterol. Nutr. 2012, 54, 164. [CrossRef] [PubMed]

17. Wlodzimirow, K.A.; Eslami, S.; Chamuleau, R.A.F.M.; Nieuwoudt, M.; Abu-Hanna, A. Prediction of poor outcome in patients with acute liver failure-systematic review of prediction models. PLoS ONE 2012, 7, 50952. [CrossRef] [PubMed]

18. Samuel, D.; Ichai, P. Prognosis indicator in acute liver failure: Is there a place for cell death markers? J. Hepatol. 2010, 53, 593-595. [CrossRef] [PubMed]

19. D'Agostino, D.; Diaz, S.; Sanchez, M.C.; Boldrini, G. Management and prognosis of acute liver failure in children. Curr Gastroenterol. Rep. 2012, 14, 262-269. [CrossRef]

20. Lu, B.R.; Zhang, S.; Narkewicz, M.R.; Belle, S.H.; Squires, R.H.; Sokol, R.J. Evaluation of the liver injury unit scoring system to predict survival in a multinational study of pediatric acute liver failure. J. Pediatr. 2013, 162, 1010-1016.e4. [CrossRef]

21. Mishra, A.; Rustgi, V. Prognostic models in acute liver failure. Clin. Liver Dis. 2018, 22, 375-388. [CrossRef]

22. Bansai, S.; Dhawan, A. Acute liver failure. Curr. Pediatr. 2006, 16, 36-42. [CrossRef]

23. Bernal, W.; Auzinger, G.; Dhawan, A.; Wendon, J. Acute liver failure. Lancet 2010, 376, 190-201. [CrossRef]

24. Bernuau, J.; Rueff, B.; Benhamou, J.P. Fulminant and subfulminant liver failure: Definitions and causes. Semin. Liver Dis. 1986, 6 , 97-106. [CrossRef] [PubMed]

25. Grama, A.; Burac, L.; Aldea, C.O.; Bulata, B.; Delean, D.; Samasca, G.; Abrudan, C.; Sirbe, C.; Pop, T.L. Vitamin D-binding protein (Gc-Globulin) in acute liver failure in children. Diagnostics 2020, 10, 278. [CrossRef] [PubMed]

26. Du, W.B.; Pan, X.P.; Li, L.J. Prognostic models for acute liver failure. Hepatobiliary Pancreat. Dis. Int. 2010, 9, 122-128. [PubMed]

27. Bhatia, V.; Singh, R.; Acharya, S.K. Predictive value of arterial ammonia for complications and outcome in acute liver failure. Gut 2006, 55, 98-104. [CrossRef] [PubMed]

28. Bernal, W.; Wendon, J. Acute liver failure. N. Engl. J. Med. 2013, 369, 2525-2534. [CrossRef] [PubMed]

29. Ayoub, B.A.H.; Ali, M.A.H.; Salem, T.A.H.; Rizk, M.S.; Nagi, S.A.M.; Adawy, N.M. Pediatric chronic liver failure-sequential organ failure assessment score and outcome of acute liver failure in children. Clin. Exp. Hepatol. 2020, 6, 228-234. [CrossRef] [PubMed]

30. Tissières, P.; Prontera, W.; Chevret, L.; Devictor, D. The pediatric risk of mortality score in infants and children with fulminant liver failure. Pediatr. Transplant. 2003, 7, 64-68. [CrossRef]

31. O'Grady, J.G. Prognostication in acute liver failure: A tool or an anchor? Liver Transpl. 2007, 13, 786-787. [CrossRef]

32. Vulturar, R.; Nicolescu, A.; Pop, T.; Deleanu, C. NMR Spectroscopy as a tool in differential diagnosis, our experience in a patient suspected for tyrosinemia type I. J. Inherit. Metab. Dis. 2015, 38, S144.

33. Vulturar, R.; Nicolescu, A.; Pop, T.L.; Tatar, S.; Deleanu, C. Biochemical and clinical aspects in several patients with galactose-1phosphate uridyl transferase deficiency. J. Inherit. Metab. Dis. 2016, 39, 148.

34. McDiarmid, S.V.; Anand, R.; Lindblad, A.S.; Principal investigators and institutions of the studies of pediatric liver transplantation (SPLIT) research group. Development of a pediatric end-stage liver disease score to predict poor outcome in children awaiting liver transplantation. Transplantation 2002, 74, 173-181. [CrossRef]

35. Kamath, P.S.; Wiesner, R.H.; Malinchoc, M.; Kremers, W.; Therneau, T.M.; Kosberg, C.L.; D'Amico, G.; Dickson, E.R.; Kim, W.R. A model to predict survival in patients with end-stage liver disease. Hepatology 2001, 33, 464-470. [CrossRef] [PubMed]

36. Ruf, A.E.; Kremers, W.K.; Chavez, L.L.; Descalzi, V.I.; Podesta, L.G.; Villamil, F.G. Addition of serum sodium into the MELD score predicts waiting list mortality better than MELD alone. Liver Transpl. 2005, 11, 336-343. [CrossRef] [PubMed]

37. Sundaram, V.; Shneider, B.L.; Dhawan, A.; Ng, V.L.; Im, K.; Belle, S.; Squires, R.H. King's college hospital criteria for nonacetaminophen induced acute liver failure in an international cohort of children. J. Pediatr. 2013, 162, 319-323.e1. [CrossRef] [PubMed]

38. Nazer, H.; Ede, R.J.; Mowat, A.P.; Williams, R. Wilson's disease: Clinical presentation and use of prognostic index. Gut 1986, 27, 1377-1381. [CrossRef]

39. Dhawan, A.; Taylor, R.M.; Cheeseman, P.; de Silva, P.; Katsiyiannakis, L.; Mieli-Vergani, G. Wilson's disease in children: 37-year experience and revised King's for liver transplantation. Liver Transpl. 2005, 11, 441-448. [CrossRef]

40. Goksuluk, D.; Korkmaz, S.; Zararsiz, G.; Karaagaoglu, A.E. EasyROC: An interactive web-tool for roc curve analysis using r language environment. $R$ J. 2016, 8, 213-230. [CrossRef]

41. Cholongitas, E.; Theocharidou, E.; Vasianopoulou, P.; Betrosian, A.; Shaw, S.; Patch, D.; O’Beirne, J.; Agarwal, B.; Burroughs, A.K. Comparison of the sequential organ failure assessment score with the King's college hospital criteria and the model for end-stage liver disease score for the prognosis of acetaminophen-induced acute liver failure. Liver Transpl. 2012, 18, 405-412. [CrossRef]

42. Rivera-Penera, T.; Moreno, J.; Skaff, C.; McDiarmid, S.; Vargas, J.; Ament, M.E. Delayed encephalopathy in fulminant hepatic failure in the pediatric population and the role of liver transplantation. J. Pediatr. Gastroenterol. Nutr. 1997, 24, 128-134. [CrossRef]

43. Mochida, S.; Nakayama, N.; Matsui, A.; Nagoshi, S.; Fujiwara, K. Re-evaluation of the guideline published by the acute liver failure study group of Japan in 1996 to determine the indications of liver transplantation in patients with fulminant hepatitis. Hepatol. Res. 2008, 38, 970-979. [CrossRef] 
44. Ciocca, M.; Ramonet, M.; Cuarterolo, M.; López, S.; Cernadas, C.; Álvarez, F. Prognostic factors in paediatric acute liver failure. Arch. Dis. Child 2008, 93, 48-51. [CrossRef]

45. Dhiman, R.K.; Jain, S.; Maheshwari, U.; Bhalla, A.; Sharma, N.; Ahluwalia, J.; Duseja, A.; Chawla, Y. Early indicators of prognosis in fulminant hepatic failure: An assessment of the model for end-stage liver disease (MELD) and King's college hospital criteria. Liver Transpl. 2007, 13, 814-821. [CrossRef] [PubMed]

46. Stravitz, R.T.; Ellerbe, C.; Durkalski, V.; Reuben, A.; Lisman, T.; Lee, W.M. Thrombocytopenia is associated with multi-organ system failure in patients with acute liver failure. Clin. Gastroenterol. Hepatol. 2016, 14, 613-620.e4. [CrossRef] [PubMed]

47. Liu, J.; Dong, R.; Chen, G.; Dong, K.; Zheng, S. Risk factors and prognostic effects of cholangitis after Kasai procedure in biliary atresia patients: A retrospective clinical study. J. Pediatr. Surg. 2019, 54, 2559-2564. [CrossRef] [PubMed]

48. Schiødt, F.V. Gc-globulin in liver disease. Dan. Med. Bull. 2008, 55, 131-146. [PubMed]

49. Schiodt, F.V.; Bondesen, S.; Tygstrup, N. Serial measurements of serum Gc-globilin in acetaminophen intoxication. Eur. J. Gastroenterol. Hepatol. 1995, 7, 635-640. [PubMed]

50. Schiødt, F.V.; Ott, P.; Tygstrup, N.; Dahl, B.; Bondesen, S. Temporal profile of total, bound, and free Gc-globulin after acetaminophen overdose. Liver Transpl. 2001, 7, 732-738. [CrossRef] [PubMed]

51. Schiødt, F.V.; Bondesen, S.; Petersen, I.; Dalhoff, K.; Ott, P.; Tygstrup, N. Admission levels of serum Gc-globulin: Redictive value in fulminant hepatic failure. Hepatology 1996, 23, 713-718. [CrossRef] [PubMed]

52. Schiødt, F.V.; Rossaro, L.; Stravitz, R.T.; Shakil, A.O.; Chung, R.T.; Lee, W.M. Gc-globulin and prognosis in acute liver failure. Liver Transpl. 2005, 11, 1223-1227. [CrossRef] [PubMed]

53. Schmidt, L.E.; Dalhoff, K. Serum phosphate is an early predictor of outcome in severe acetaminophen-induced hepatotoxicity. Hepatology 2002, 36, 659-665. [CrossRef]

54. Craig, D.G.N.; Ford, A.C.; Hayes, P.C.; Simpson, K.J. Systematic review: Prognostic tests of paracetamol-induced acute liver failure. Aliment. Pharmacol. Ther. 2010, 31, 1064-1076. [CrossRef]

55. Rosen, H.R.; Biggins, S.W.; Niki, T.; Gralla, J.; Hillman, H.; Hirashima, M.; Schilsky, M.; Lee, W.M.; Acute liver failure study group. Association between plasma level of galectin-9 and survival of patients with drug-induced acute liver failure. Clin. Gastroenterol. Hepatol. 2016, 14, 606-612.e3. [CrossRef] [PubMed]

56. Craig, D.G.; Simpson, K.J. Accuracy of the ALFSG index as a triage marker in acute liver failure. Gastroenterology 2013, 144, e25. [CrossRef] [PubMed]

57. Dhawan, A.; Cheeseman, P.; Mieli-Vergani, G. Approaches to acute liver failure in children. Pediatr. Transplant. 2004, 8, 584-588 [CrossRef] [PubMed]

58. Rajanayagam, J.; Coman, D.; Cartwright, D.; Lewindon, P.J. Pediatric acute liver failure: Etiology, outcomes, and the role of serial pediatric end-stage liver disease scores. Pediatr. Transplant. 2013, 17, 362-368. [CrossRef] [PubMed]

59. Durand, P.; Debray, D.; Mandel, R.; Baujard, C.; Branchereau, S.; Gauthier, F.; Jacquemin, E.; Devictor, D. Acute liver failure in infancy: A 14-year experience of a pediatric liver transplantation center. J. Pediatr. 2001, 139, 871-876. [CrossRef]

60. Rajanayagam, J.; Frank, E.; Shepherd, R.W.; Lewindon, P.J. Artificial neural network is highly predictive of outcome in paediatric acute liver failure. Pediatr. Transplant. 2013, 17, 535-542. [CrossRef]

61. McPhail, M.J.W.; Wendon, J.A.; Bernal, W. Meta-analysis of performance of King's college hospital criteria in prediction of outcome in non-paracetamol-induced acute liver failure. J. Hepatol. 2010, 53, 492-499. [CrossRef]

62. Bernal, W.; Williams, R. Beyond KCH selection and options in acute liver failure. Hepatol. Int. 2018, 12, 204-213. [CrossRef]

63. Panchal, H.J.; Durinka, J.B.; Patterson, J.; Karipineni, F.; Ashburn, S.; Siskind, E.; Ortiz, J. Survival outcomes in liver transplant recipients with model for end-stage liver disease scores of 40 or higher: A decade-long experience. HPB (Oxford) 2015, 17, 1074-1084. [CrossRef]

64. Figorilli, F.; Putignano, A.; Roux, O.; Houssel-Debry, P.; Francoz, C.; Paugam-Burtz, C.; Soubrane, O.; Agarwal, B.; Durand, F.; Jalan, R. Development of an organ failure score in acute liver failure for transplant selection and identification of patients at high risk of futility. PLOS ONE 2017, 12, 188151. [CrossRef]

65. Levesque, E.; Hoti, E.; Azoulay, D.; Ichaï, P.; Habouchi, H.; Castaing, D.; Samuel, D.; Saliba, F. Prospective evaluation of the prognostic scores for cirrhotic patients admitted to an Intensive Care Unit. J. Hepatol. 2012, 56, 95-102. [CrossRef]

66. Barshes, N.R.; Lee, T.C.; Udell, I.W.; O'Mahoney, C.A.; Karpen, S.J.; Carter, B.A.; Goss, J.A. The pediatric end-stage liver disease (PELD) model as a predictor of survival benefit and posttransplant survival in pediatric liver transplant recipients. Liver Transpl. 2006, 12, 475-480. [CrossRef]

67. Núñez-Ramos, R.; Montoro, S.; Bellusci, M.; Del Fresno-Valencia, M.R.; Germán-Díaz, M.; Urruzuno, P.; Medina, E.; Manzanares, J. Acute liver failure: Outcome and value of pediatric end-stage liver disease score in pediatric cases. Pediatr. Emerg. Care 2018, 34, 409-412. [CrossRef]

68. Yantorno, S.E.; Kremers, W.K.; Ruf, A.E.; Trentadue, J.J.; Podestá, L.G.; Villamil, F.G. MELD is superior to King's college and Clichy's criteria to assess prognosis in fulminant hepatic failure. Liver Transpl. 2007, 13, 822-828. [CrossRef]

69. McPhail, M.J.W.; Farne, H.; Senvar, N.; Wendon, J.A.; Bernal, W. Ability of King's college criteria and model for end-stage liver disease scores to predict mortality of patients with acute liver failure: A meta-analysis. Clin. Gastroenterol. Hepatol. 2016, 14, 516-525.e5. [CrossRef] [PubMed] 
70. Ng, V.L.; Li, R.; Loomes, K.M.; Leonis, M.A.; Rudnick, D.A.; Belle, S.H.; Squires, R.H. Pediatric acute liver failure study group (PALFSG). Outcomes of children with and without hepatic encephalopathy from the pediatric acute liver failure study group. $J$. Pediatr. Gastroenterol. Nutr. 2016, 63, 357-364. [CrossRef] [PubMed]

71. Schmidt, L.E.; Larsen, F.S. Prognostic implications of hyperlactatemia, multiple organ failure, and systemic inflammatory response syndrome in patients with acetaminophen-induced acute liver failure. Crit. Care Med. 2006, 34, 337-343. [CrossRef] [PubMed]

72. Kim, Y.J.; Lee, H.J.; Ryoo, S.M.; Ahn, S.; Sohn, C.H.; Seo, D.W.; Lim, K.S.; Kim, W.Y. Prognostic value of decision criteria for emergency liver transplantation in patients with wild mushroom induced acute liver injury. Hepatobiliary Pancreat. Dis. Int. 2018, 17, 210-213. [CrossRef] [PubMed]

73. Ganzert, M.; Felgenhauer, N.; Zilker, T. Indication of liver transplantation following amatoxin intoxication. J. Hepatol. 2005, 42, 202-209. [CrossRef]

74. Escudié, L.; Francoz, C.; Vinel, J.P.; Moucari, R.; Cournot, M.; Paradis, V.; Sauvanet, A.; Belghiti, J.; Valla, D.; Bernuau, J.; et al Amanita phalloides poisoning: Reassessment of prognostic factors and indications for emergency liver transplantation. J. Hepatol. 2007, 46, 466-473. [CrossRef] [PubMed]

75. Stefanescu, A.; Pop, T.; Stefanescu, H.; Feier, D.; Bizo, A.; Miu, N. 1012 serum creatinine and the presence of encephalopathy at presentation may predict mortality in children with acute liver failure. J. Hepatol. 2013, 58, S417. [CrossRef]

76. Pop, T.L.; Grama, A.; Stefanescu, A.; Delean, D.; Aldea, C.; Bizo, A. PELD score as a prognostic factor in fulminant liver failure caused by mushroom poisoning in children. J. Hepatol. 2016, 64, S304-S305. [CrossRef]

77. Grama, A.; Aldea, C.; Burac, L.; Delean, D.; Boghitoiu, D.; Bulata, B.; Nitescu, V.; Ulmeanu, C.; Pop, T.L. Acute liver failure secondary to toxic exposure in children. Arch. Med. Sci. 2022, 18. [CrossRef]

78. Kamath, P.S.; Heimbach, J.; Wiesner, R.H. Acute liver failure prognostic scores: Is good enough good enough? Clin. Gastroenterol. Hepatol. 2016, 14, 621-623. [CrossRef]

79. Sankar, J. Acute physiology and chronic health evaluation II for critically ill children? Indian J. Crit. Care Med. 2015, 19, 446-448. [CrossRef]

80. Cholongitas, E.B.; Betrossian, A.; Leandro, G.; Shaw, S.; Patch, D.; Burroughs, A.K. King's criteria, APACHE II, and SOFA scores in acute liver failure. Hepatology 2006, 43, 881. [CrossRef]

81. Rutherford, A.; King, L.Y.; Hynan, L.S.; Vedvyas, C.; Lin, W.; Lee, W.M.; Chung, R.T.; ALF study group. Development of an accurate index for predicting outcomes of patients with acute liver failure. Gastroenterology 2012, 143, 1237-1243. [CrossRef]

82. Kumar, R.; Sharma, H.; Goyal, R.; Kumar, A.; Khanal, S.; Prakash, S.; Gupta, S.D.; Panda, S.K.; Acharya, S.K. Prospective derivation and validation of early dynamic model for predicting outcome in patients with acute liver failure. Gut 2012, 61, 1068-1075. [CrossRef]

83. Oliveira, V.M.; Brauner, J.S.; Rodrigues Filho, E.; Susin, R.G.; Draghetti, V.; Bolzan, S.T.; Vieira, S.R. Is SAPS 3 better than APACHE II at predicting mortality in critically ill transplant patients? Clinics (Sao Paulo Braz.) 2013, 68, 153-158. [CrossRef]

84. Matthews, C.E.; Goonasekera, C.; Dhawan, A.; Deep, A. Validity of pediatric index of mortality 2 (PIM2) score in pediatric acute liver failure. Crit. Care 2014, 18, 665. [CrossRef] [PubMed]

85. Lu, B.R.; Gralla, J.; Liu, E.; Dobyns, E.L.; Narkewicz, M.R.; Sokol, R.J. Evaluation of a scoring system for assessing prognosis in pediatric acute liver failure. Clin. Gastroenterol. Hepatol. 2008, 6, 1140-1145. [CrossRef]

86. Socha, P.; Janczyk, W.; Dhawan, A.; Baumann, U.; D'Antiga, L.; Tanner, S.; Iorio, R.; Vajro, P.; Houwen, R.; Fischler, B.; et al. Wilson's disease in children: A position paper by the hepatology committee of the European Society for paediatric gastroenterology, hepatology and nutrition. J. Pediatr. Gastroenterol. Nutr. 2018, 66, 334-344. [CrossRef] 